\title{
Análise de representações de fluxos migratórios contemporâneos na narrativa jornalística brasileira sob a perspectiva do conceito de pânico moral Analysis of representations of contemporaries migratory flows in the Brazilian journalistic narrative from the perspective of moral panic concept
}

\author{
Samira Moratti Frazão \\ Doutoranda no Programa de Pós-Graduação em História da Universidade do Estado de Santa Catarina, Brasil. E-mail: \\ samiramoratti@gmail.com \\ Gláucia de Oliveira Assis \\ Docente na Universidade do Estado de Santa Catarina, Brasil. Doutora em Ciências Sociais pela Universidade Estadual de \\ Campinas, Brasil. E-mail: galssis@gmail.com
}

\begin{abstract}
Resumo:
A partir da análise de um caso de suspeita de ebola no Brasil em 2014, envolvendo um refugiado de origem africana, a proposta do artigo, recorte de tese em andamento, foi problematizar como o refugiado foi representado na cobertura (tele)jornalística e como se deu a construção dessa realidade. Acredita-se que a abordagem jornalística pode ter contribuído para a disseminação de um pânico moral na sociedade brasileira, desencadeando manifestações racistas e xenofóbicas nos canais pelos quais o público emite opinião em sites jornalísticos. Foram analisadas duas reportagens de um total de 68 publicadas em outubro de 2014 em sites jornalísticos brasileiros, por meio do método Análise de Conteúdo. As reportagens expuseram o refugiado como "ameaça", marginalizando-o e impactando negativamente na inserção e integração de outros imigrantes e refugiados contemporâneos.
\end{abstract}

\section{Palavras-chave:}

Pânico moral; Fluxos migratórios contemporâneos; Racismo; História do tempo presente; Narrativa jornalística.

\begin{abstract}
:
Based on the analysis of a case of suspected ebola in Brazil in 2014, involving an African refugee, this article proposal, part of a thesis in progress, discuss how the refugee was presented in the journalistic coverage and how this construction of reality was made. We believe that this journalistic approach may have contributed to the spread of moral panic in Brazilian society, triggering racist and xenophobic manifestations from the public. Two news articles from a total of 68 published in October 2014 on Brazilian journalistic sites were analyzed using the Content
\end{abstract}

INTERIN, v. 22, n. 1, jan./jun. 2017. ISSN: 1980-5276.

Samira Moratti Frazão; Gláucia de Oliveira Assis. Análise de representações de fluxos migratórios contemporâneos na narrativa jornalística brasileira sob a perspectiva do conceito de pânico moral. p. 111-130. 
Analysis method. We observed what the news exposed the refugee as a "threat", marginalizing him and negatively impacting on the insertion and integration of other contemporary immigrants and refugees.

\section{Keywords:}

Moral panic; Contemporary migratory flows; Racism; History of the present time; Journalistic Narrative.

\section{Percurso introdutório sobre o problema de pesquisa}

A partir da primeira década do século XXI, o número de refugiados no Brasil aumentou de forma crescente ano após ano, de acordo com informações divulgadas em abril de 2016 pelo Comitê Nacional para os Refugiados (Conare), órgão ligado à Secretaria Nacional de Justiça brasileira. Entre os anos de 2010 e 2015, registrou-se uma ampliação de 2.868\% nas solicitações de refúgio no país. Em 2010, por exemplo, foram recebidas 966 solicitações; em 2015 esse número alcançou a marca de 28.670 pedidos. Atualmente vivem no país cerca de 8.863 refugiados reconhecidos, entre homens, mulheres e crianças, de 79 nacionalidades, em especial da África, Ásia, Oriente Médio e Caribe (ACNUR, 2016).

Entre os inúmeros relatos envolvendo fluxos migratórios contemporâneos no Brasil midiatizados em jornais nacionais está o de um refugiado da Guiné, que deu entrada no país entre os meses de agosto e outubro de 2014. Ele foi envolvido em um caso de suspeita de ebola ocorrido naquele ano. O fato gerou repercussão tal que posteriormente foram narrados episódios de racismo e xenofobia contra imigrantes e refugiados africanos, bem como contra negros de outras nacionalidades. Durante a cobertura jornalística sobre a suspeita de ebola em 2014, “... imigrantes negros - na sua maioria haitianos e de países africanos - [foram] alvo de discriminação e atitudes hostis, nas redes sociais e em Cascavel (PR), cidade aonde o homem vindo da Guiné foi atendido inicialmente" (RICHARD, 2014, grifo nosso), de acordo com reportagem publicada no site Agência Brasil, em 16 de outubro de 2014.

Em virtude do sensacionalismo gerado em torno desse caso em particular, ao analisar reportagens publicadas em sites jornalísticos e portais de telejornais 
brasileiros na internet, foi possível notar que o discurso promovido divergia no que diz respeito à abordagem. Enquanto de um lado o enquadramento dado tratava da fragilidade e vulnerabilidade da vida do refugiado em questão, de outro lado o discurso jornalístico expôs informações que o deixaram sob suspeita, colocando sua integridade física e moral em xeque. Essa construção da realidade também levava a crer que outros imigrantes e refugiados, sobretudo os que eram negros ou estavam indocumentados, eram passíveis de ter contraído o ebola.

Pesquisar desdobramentos como o que se apresenta, e que se relacionam ao macro tema mídia e migrações, faz-se necessário e urgente, uma vez que a mídia promove representações da realidade as quais propõem à sociedade informação, constituindo uma das bases para a construção da opinião pública (VIZEU, 2009). No caso do jornalismo audiovisual, cujas reportagens também integram o corpus de análise do presente artigo, as narrativas por meio das imagens “... constituem um discurso que interfere na realidade, constrói e reconstrói relações sociais e relações de poder" (MOTA, 2012, p. 213). Portanto, ainda que esse problema de pesquisa seja debatido com outros pontos de vista, há a necessidade de problematizar a questão e desconstruir as representações apresentadas, a fim de analisar os desdobramentos sobre a inserção de imigrantes e refugiados no Brasil e os impactos que tais representações geram não apenas na vida da comunidade migrante e em situação de refúgio, mas na sociedade que deveria acolher essas pessoas.

Parte-se da hipótese de que o modo como foram construídas as representações presentes na narrativa de notícias, textuais e audiovisuais, divulgadas em sites jornalísticos sobre o refugiado com origem da Guiné, apontado à época como suspeito de ter contraído o vírus ebola, podem ter contribuído para a disseminação de um pânico moral na sociedade brasileira, desencadeando manifestações racistas e de ódio contra os fluxos (i)migratórios contemporâneos, nos canais onde o público pode emitir sua opinião, nos próprios sites de notícias e em outras redes sociais.

A fim de testar a hipótese, foi realizada a análise de um grupo composto por 68 reportagens, do qual foram selecionadas duas para este artigo, sendo uma veiculada em 12 de outubro de 2014 na revista eletrônica "Fantástico", exibida na

INTERIN, v. 22, n. 1, jan./jun. 2017. ISSN: 1980-5276.

Samira Moratti Frazão; Gláucia de Oliveira Assis. Análise de representações de fluxos migratórios contemporâneos na narrativa jornalística brasileira sob a perspectiva do conceito de pânico moral. p. 111-130. 
Rede Globo de Televisão e, posteriormente, disponibilizada no site do programa, e a outra no dia 19 de outubro de 2014 no site do "Jornal do Brasil", cujas informações foram detalhadas adiante.

Vistas enquanto documentos que, neste caso em particular, constroem narrativas sobre a migração, as reportagens marcaram e marcam a história política, cultural e social do Brasil e, em parte dos casos, não estão disponíveis de forma acessível aos pesquisadores e sociedade. Eis a importância adicional em analisar como essas informações são elaboradas e como acabam por constituir a história pública em torno dos fluxos migratórios contemporâneos.

A fim de analisar o presente problema de pesquisa, o artigo é apoiado nos conceitos de representação postulados por Roger Chartier e Patrick Charaudeau, e de narrativa, discutido por autores como Paul Ricoeur e, no âmbito da Comunicação/Jornalismo, por Luiz Gonzaga Motta e Célia Ladeira Mota, bem como o conceito de pânico moral, com base nos estudos do sociólogo Kenneth Thompson. No que diz respeito aos refugiados, são tomados como base documentos oficiais, como a Convenção de 1951, que estabelece o Estatuto do Refugiado pelas Nações Unidas e a lei brasileira 9.474/97, que constitui os direitos e deveres do refugiado no Brasil, dentre outros documentos.

\section{Representações nas narrativas jornalísticas: alguns insumos teóricos}

O conceito de representação formulado pelo historiador francês Roger Chartier pode dialogar e ser aqui usado para pensar o discurso disposto nas matérias jornalísticas, analisando não apenas o texto presente na reportagem, como também para pensar a imagem enquanto linguagem e mensagem, apreendida pelos espectadores de maneiras diferentes.

Nesse sentido, o conceito pode tratar da “... relação entre a significação, a realidade e sua imagem" (CHARAUDEAU, 2014, p. 431). Por meio das representações, os indivíduos conferem sentido à realidade em seu ambiente social.

INTERIN, v. 22, n. 1, jan./jun. 2017. ISSN: 1980-5276.

Samira Moratti Frazão; Gláucia de Oliveira Assis. Análise de representações de fluxos migratórios contemporâneos na narrativa jornalística brasileira sob a perspectiva do conceito de pânico moral. p. 111-130. 
No entanto, pressupõem ideais, interesses e ideologias lideradas por grupos que detêm o poder (CHARTIER, 1990, 1991). Desse modo, as informações recebidas por meio da mídia são componentes na construção da realidade e na formação da opinião da sociedade a respeito de determinado tema.

O discurso, tanto textual, quanto imagético, sobre determinado fato ou pessoa pode transmitir ao público a representação do que se pensa ou se almeja moldar do que é e como deve ser visto. Esse discurso jornalístico também pode ser permeado por omissões de informação, falta de conhecimento quando da elaboração e produção da reportagem em um curto espaço de tempo, edição do material, enquadramento das imagens e escolhas de quais recortes de imagem serão privilegiados.

Assim, versões da realidade podem ser representadas com base em fatos verídicos ou moldados de acordo com os interesses da linha editorial do veículo jornalístico, ou ainda de patrocinadores e demais sujeitos que detenham algum poder sobre o conteúdo que será produzido. “... As representações constroem uma organização do real por meio das próprias imagens mentais veiculadas por um discurso" (CHARAUDEAU, 2014, p. 433).

Além dos interesses estabelecidos pelos sujeitos que as editam, o suporte no qual as informações serão veiculadas também propicia que determinados conteúdos sejam adaptados conforme as características do meio. Ainda que trate da linguagem textual, a discussão de Chartier também poderia ser adequada ao jornalismo audiovisual. “... É preciso lembrar que não há texto fora do suporte que lhe permite ser lido (ou ouvido) e que não há compreensão de um escrito, qualquer que seja, que não dependa das formas pelas quais atinge o leitor" (CHARTIER, 1991, s. p.).

A fim de refinar o debate em torno do conceito, também cabe aqui entender o que vem a ser a narrativa e como dialoga com as representações sociais. "Estudar as narrativas como representações sociais pode ensinar muito sobre as maneiras através das quais os homens constroem essas representações do mundo material e social" (MOTTA, 2012, p. 29).

Estudioso das obras de Paul Ricoeur, Aldo Nelson Bona (2012) cita que embora seja impossível narrar o modo como os fatos ocorreram no passado ou em

INTERIN, v. 22, n. 1, jan./jun. 2017. ISSN: 1980-5276.

Samira Moratti Frazão; Gláucia de Oliveira Assis. Análise de representações de fluxos migratórios contemporâneos na narrativa jornalística brasileira sob a perspectiva do conceito de pânico moral. p. 111-130. 
outro momento do tempo, para Ricoeur a história é considerada uma narrativa. Desse modo, não deve ser compreendida como mera descrição dos acontecimentos, mas confere a eles sentido; ou seja, atribui-se sentido a algo real que é descrito, não necessariamente ao modo como aconteceu.

E nesse processo de atribuição de sentido, com base em construções da realidade, o tema ou as pessoas que são representadas na narrativa jornalística podem ser ou beneficiados ou prejudicados. No problema de estudo aqui apresentado para reflexão, percebeu-se que os fluxos migratórios contemporâneos foram, de modo geral, marginalizados e colocados no centro de um julgamento moral por parte da sociedade brasileira atenta ao tema das migrações.

Há a necessidade, então, de diferenciar o significado de estar refugiado e os direitos e deveres a eles dedicados, com base na legislação internacional e nacional, para tentar compreender as imbricações que tais representações da realidade podem acarretar em seu processo de inserção e integração.

\section{Quem são os refugiados?}

Nesse ensejo, quais fatores são determinantes para caracterizar o refúgio? A Convenção das Nações Unidas sobre o Estatuto dos Refugiados, instituída em 28 de julho de 1951 em decorrência da realização da Conferência das Nações Unidas de Plenipotenciários, em Genebra, estabeleceu instrumentos legais e que vigoram internacionalmente a respeito dos direitos dos refugiados. Nela é possível delinear padrões básicos para o tratamento e acolhimento de pessoas em situação de refúgio. No artigo $1^{\circ}$, letra $\mathrm{A}$, item 2 , a Convenção estabelece o refugiado como sendo a pessoa que

[...] temendo ser perseguida por motivos de raça, religião, nacionalidade, grupo social ou opiniões políticas, se encontra fora do país de sua nacionalidade e que não pode ou, em virtude desse temor, não quer valerse da proteção desse país, ou que, se não tem nacionalidade e se encontra fora do país no qual tinha sua residência habitual em consequência de tais acontecimentos, não pode ou, devido ao referido temor, não quer voltar a

INTERIN, v. 22, n. 1, jan./jun. 2017. ISSN: 1980-5276.

Samira Moratti Frazão; Gláucia de Oliveira Assis. Análise de representações de fluxos migratórios contemporâneos na narrativa jornalística brasileira sob a perspectiva do conceito de pânico moral. p. 111-130. 
ele. No caso de uma pessoa que tem mais de uma nacionalidade, a expressão "do país de sua nacionalidade" se refere a cada um dos países dos quais ela é nacional. (ACNUR, 2015a).

Um protocolo adicional foi lançado em 1967. O novo documento propôs novas categorias para determinar as situações pelas quais uma pessoa se torna refugiada. Por sua vez, o protocolo de 1967 determinou, no artigo 1 das "Disposições Gerais", parágrafo 2, que o Estatuto dos Refugiados proteja não apenas os perseguidos das grandes guerras anteriores a 1951, mas de diversos outros conflitos de ordem humana e/ou ambiental posteriores à data:

§2. Para os fins do presente Protocolo, o termo "refugiado", salvo no que diz respeito à aplicação do $\S 3$ do presente artigo, significa qualquer pessoa que se enquadre na definição dada no artigo primeiro da Convenção, como se as palavras "em decorrência dos acontecimentos ocorridos antes de $1^{\circ}$ de janeiro de 1951 e..." e as palavras "...como conseqüência de tais acontecimentos" não figurassem do $§ 2$ da seção $\mathrm{A}$ do artigo primeiro. (ACNUR, 1967).

O protocolo estabeleceu ainda que os Estados signatários da Convenção cooperassem com o ACNUR e com quaisquer órgãos ligados às Nações Unidas, no que diz respeito à garantia dos direitos humanos de refugiados (ACNUR, 1967).

Por sua vez, a lei brasileira n. 9.474, de 22 de julho de 1997, que define mecanismos legais para a implementação da Convenção de 1951, apresenta a definição e os direitos e deveres a quem está nesta condição. Basicamente segue os mesmos preceitos fundados no documento de 1951, reforçando adicionalmente condições, como a violação grave aos direitos humanos como um dos fatores que faz com que uma pessoa venha a solicitar asilo como refugiado em outro país. Poderá entrar em solo nacional mesmo que esteja em situação irregular, quando sua entrada não é feita de forma legal, cabendo ao Conare avaliar os pedidos de refúgio, dentre outras circunstâncias que envolvam pessoas em situação de refúgio no Brasil. Posteriormente a Polícia Federal emite um protocolo por meio do qual o refugiado poderá solicitar carteira de trabalho e seu Cadastro de Pessoa Física (CPF) em caráter

INTERIN, v. 22, n. 1, jan./jun. 2017. ISSN: 1980-5276.

Samira Moratti Frazão; Gláucia de Oliveira Assis. Análise de representações de fluxos migratórios contemporâneos na narrativa jornalística brasileira sob a perspectiva do conceito de pânico moral. p. 111-130. 
provisório. Após o término do processo, caso seu pedido de refúgio seja aceito, receberá as documentações em caráter permanente (BRASIL, 1997).

Caso o pedido seja negado, o solicitante de refúgio dispõe de um período estabelecido por lei para solicitar a revisão do resultado e do pedido junto ao Ministro de Estado da Justiça. E, mesmo que o pedido seja negado em definitivo, o refugiado não poderá ser deportado ao seu país em consideração às premissas que estabelecem sua condição. Somente poderá ser deslocado para outro país caso não corra risco de perseguição.

É importante salientar, ainda, que o governo de origem de quem requisita o refúgio necessariamente não precisa aprovar sua condição; cabe ao país de acolhimento conceder-lhe este reconhecimento. De acordo com o ACNUR, apesar de os países signatários da Convenção de Genebra disporem de instrumentos legais por meio dos quais irão analisar os pedidos de refúgio, "uma pessoa é um refugiado independentemente de já lhe ter sido ou não reconhecido esse status por meio de um processo legal de elegibilidade" (ACNUR, 2015b). E estabelece ainda: “Ao ACNUR é atribuído o mandato de assegurar que qualquer pessoa, em caso de necessidade, possa exercer o direito de buscar e obter refúgio em outro país e, caso deseje, regressar ao seu país de origem" (ACNUR, 2015b).

No entanto, para ser considerado um refugiado, o imigrante que solicita auxílio no Brasil passa por um processo que pode durar anos para que seu refúgio seja reconhecido de fato. Enquanto aguarda esse processo, deve seguir os preceitos determinados na Lei n. 6.815, de 1980, que implementou o Estatuto do Estrangeiro. Em virtude de sua concepção datar de um período considerado historicamente antidemocrático, momento no qual vigorou o regime ditatorial militar no Brasil (1964-1985), tal lei é vista com cautela por organizações não-governamentais, instituições religiosas, entidades públicas e da esfera civil que intercedem pela causa migratória e do refúgio no país. Por esse e dentre outros motivos, uma nova lei das migrações foi elaborada a fim de substituir o Estatuto do Estrangeiro de 1980.

O Conselho Nacional de Imigração (CNIg), responsável por articular a Política Migratória Brasileira por meio da Política de Migração Laboral, e o

INTERIN, v. 22, n. 1, jan./jun. 2017. ISSN: 1980-5276.

Samira Moratti Frazão; Gláucia de Oliveira Assis. Análise de representações de fluxos migratórios contemporâneos na narrativa jornalística brasileira sob a perspectiva do conceito de pânico moral. p. 111-130. 
Ministério do Trabalho estão à frente de um projeto de lei, o PL 5.655/2009, apensado ao PL de número 2.516/2015, que visa instituir uma nova Lei de Migração ${ }^{1}$. Se aprovada e sancionada, a nova lei apontará garantias no que compete aos direitos humanos para os trabalhadores imigrantes, cujos anseios não são amparados no Estatuto do Estrangeiro de 1980, bem como a transformação do CNIg, que atualmente compreende apenas imigrantes, em Conselho Nacional de Migração, o que também possibilitará a reflexão em torno de políticas migratórias que também comtemplem os emigrantes brasileiros (ASSIS; MAGALHÃES, 2016).

Munidos com insumo para compreender o status de refugiado, que pode ser concedido a alguém que requeira tal situação, vamos entender agora como é constituído o significado de pânico moral para, posteriormente, proceder à análise empírica do presente objeto de estudo.

\section{Pânico moral: pistas para compreender o conceito}

As construções de realidade elaboradas no jornalismo podem contribuir para a criação de estereótipos ${ }^{2}$, além de fomentar no público um pânico de ordem moral em torno de determinados assuntos dispostos na agenda jornalística. Porém, quais fatores constituem o pânico moral?

Neste momento, o conceito foi analisado com base nos estudos do sociólogo britânico Kenneth Thompson, apoiado nas pesquisas do sociólogo Stanley Cohen. O pânico moral é definido por uma reação provocada por um grupo em particular, o qual pode desencadear uma representação e percepção equivocada sobre algum comportamento cultural ou grupo de indivíduos, em especial as minorias. Desse modo, os estereótipos construídos nos meios de comunicação também podem

\footnotetext{
${ }^{1}$ Em dezembro de 2016, o projeto de lei foi aprovado pela Câmara dos Deputados e encaminhado ao Senado Federal, de acordo com informações disponíveis no site da Câmara $<$ http://www.camara.gov.br/proposicoesWeb/fichadetramitacao?idProposicao=1594910>. Acesso em: 19/12/2016.

${ }^{2}$ Por estereótipo se entende uma “... representação coletiva cristalizada, é uma construção de leitura”, permitindo “... naturalizar o discurso, esconder o cultural sob o evidente" (AMOSSY, 2014, p. 214216).
}

INTERIN, v. 22, n. 1, jan./jun. 2017. ISSN: 1980-5276. 
facilitar a promoção de um pânico moral à sociedade sobre um tema específico (THOMPSON, 2014).

$\mathrm{O}$ termo foi empregado inicialmente no campo da Sociologia, atrelado às condutas coletivas e de desvio social. É utilizado também para observar fenômenos excepcionais nos meios de comunicação. Dentre as principais características, estão:

1) algo ou alguém é definido como uma ameaça aos valores e interesses da sociedade; 2) esta ameaça se representa nos meios massivos de tal modo que sua forma será facilmente reconhecida; 3) se produz uma rápida construção de uma preocupação pública; 4) as autoridades e os formadores de opinião devem responder ou dizer algo a respeito; 5) o pânico passa ou produz mudanças sociais. (THOMPSON, 2014, p. 23).

Para Thompson, o uso dos dois termos, "pânico" e "moral", pressupõe uma ameaça ao que está estabelecido enquanto sagrado ou fundamental para a sociedade.

O motivo para denominar 'moral' ao pânico é precisamente indicar que a ameaça que se percebe não é algo trivial - um resultado econômico ou uma pauta educativa -, e sim uma ameaça à ordem social em si mesma ou a uma concepção idealizada (ideológica) de alguma parte de tal ordem social. A ameaça e seus executores são vistos como o mal, como 'demônios populares' [...] despertando fortes sentimentos de controle. (THOMPSON, 2014, p. 24).

Como resposta, exige-se que haja uma "maior regulação ou controle, uma demanda para regressar aos 'valores' tradicionais" (THOMPSON, 2014, p. 24). Somado a isso, os pânicos morais geralmente surgem em situações nas quais há um aumento de níveis de stress na população, provocados por várias origens que passam pela mídia, política, economia, dentre outros fatores. Thompson afirma que não se pode atribuir a criação de um pânico moral a apenas um segmento, mas sim a um conjunto deles. Por isso, indica que os casos de pânico moral devem levar em conta dois objetivos: compreender os atores implicados nesse processo, e buscar explicações nas razões que levaram ao desenvolvimento de um pânico moral.

Há dois elementos principais para identificar os pânicos morais: "um alto nível de preocupação pelo comportamento de um determinado grupo ou tipo de pessoas, e um aumento do nível de hostilidade a aqueles considerados como uma

INTERIN, v. 22, n. 1, jan./jun. 2017. ISSN: 1980-5276.

Samira Moratti Frazão; Gláucia de Oliveira Assis. Análise de representações de fluxos migratórios contemporâneos na narrativa jornalística brasileira sob a perspectiva do conceito de pânico moral. p. 111-130. 
ameaça" (THOMPSON, 2014, p. 24). Ademais, os pânicos morais geralmente são voláteis, durando um certo período de tempo, e desproporcionais, já que nem sempre tais ameaças ou perigos atribuídos ao pânico moral são de fato consideráveis, caso se analise o fenômeno de forma realista e não apenas com base em suposições.

Considerando o exposto, acredita-se ser possível utilizar o conceito para analisar a abordagem na narrativa jornalística digital e audiovisual a respeito dos novos fluxos migratórios. Para tanto, será utilizado o caso de suspeita de ebola ocorrido no Brasil em outubro de 2014 e que envolveu um refugiado da Guiné. $\mathrm{Na}$ ocasião, segmentos do jornalismo, seguidos de comentários realizados por parte da sociedade, marginalizaram o refugiado com suspeita de ter contraído a doença, a ponto de gerar reflexos sobre a inserção e integração de outros migrantes e refugiados de origem africana ou negros de outras nacionalidades que estavam em mobilidade no Brasil naquele momento.

Nesse contexto é oportuno tratar sobre o racismo, componente ainda presente na sociedade brasileira contemporânea, fator que também incide sobre o acolhimento de imigrantes, sobretudo negros, que tomam o Brasil como destino de seus fluxos migratórios.

Entre meados do século XIX e século XX, ações políticas permeadas pela ideologia de branqueamento visavam a criação de uma sociedade branca e ocidental contando, para tanto, com a imigração de migrantes europeus, vindos de países como Portugal, Itália, Alemanha e Espanha, que vieram ao Brasil em busca de trabalho. Tais políticas também contribuíram para promover uma cultura racista, na qual a população negra, em muitos casos marginalizada e sem garantias e direitos para sua subsistência, era vista como ameaça. Logo, a ideia era provocar a mistura de raças, a fim de promover o branqueamento da população ao longo do tempo (BENTO, 2002).

Soma-se a isso a colonização de diversas regiões brasileiras, notadamente a região sul, realizada sobretudo por migrantes brancos de origem europeia, cujos reflexos são facilmente notados por meio de celebrações feitas em festas sazonais ou mesmo pela existência de monumentos físicos ou imateriais ligados às culturas de origem europeia, sobretudo de países como Itália, Portugal e Alemanha. No entanto,

INTERIN, v. 22, n. 1, jan./jun. 2017. ISSN: 1980-5276.

Samira Moratti Frazão; Gláucia de Oliveira Assis. Análise de representações de fluxos migratórios contemporâneos na narrativa jornalística brasileira sob a perspectiva do conceito de pânico moral. p. 111-130. 
há que se ressaltar que na mesma medida em que uma parcela da população é reticente ou contrária a esses novos fluxos migratórios, outra faz frente e apoia a inserção e integração dos migrantes em seu convívio social, principalmente aquelas ligadas aos Direitos Humanos, Relações Internacionais, Serviço Social, dentre outras áreas.

Tais pressupostos teóricos serão, neste momento, alicerçados com base na análise da cobertura midiática que se segue.

\section{Análise das reportagens}

Foram utilizadas duas reportagens, sendo uma veiculada no dia 12 de outubro de 2014 na revista eletrônica semanal "Fantástico", exibida pela Rede Globo e, posteriormente, disponibilizada em seu site na internet, e a outra publicada na versão digital do "Jornal do Brasil", no dia 19 de outubro de 2014. Como método, foi usado neste momento a Análise de Conteúdo.

O método pode ser utilizado para “... avaliar características da produção de indivíduos, grupos e organizações, para identificar elementos típicos, exemplos representativos e discrepâncias e para comparar o conteúdo jornalístico de diferentes mídias em diferentes culturas" (HERSCOVITZ, 2007, p. 123). Isso porque pode ser uma ferramenta que auxilia na compreensão tanto de quem produz o discurso, quanto de quem o recebe, compreendendo características presentes na produção, emissão e recepção dessas notícias. Desse modo, acreditou-se que, neste momento, foi útil para avaliar ambas as reportagens selecionadas e cuja análise foi, resumidamente, disposta a seguir.

Intitulada "Africano com suspeita de ebola esperou por 4 horas até ser atendido", a reportagem veiculada no Fantástico em 12 de outubro de 2014 (FANTÁSTICO, 2014) dava continuidade a cobertura jornalística realizada pelos demais programas e veículos jornalísticos da Rede Globo sobre o então considerado primeiro caso de suspeita de ebola no Brasil, ocorrido em 9 de outubro de 2014,

INTERIN, v. 22, n. 1, jan./jun. 2017. ISSN: 1980-5276.

Samira Moratti Frazão; Gláucia de Oliveira Assis. Análise de representações de fluxos migratórios contemporâneos na narrativa jornalística brasileira sob a perspectiva do conceito de pânico moral. p. 111-130. 
envolvendo um refugiado que havia chegado ao país vindo da Guiné à época e que apresentava sintomas do vírus. A Guiné estava naquele momento passando por um surto da doença, fator que inclusive estava motivando tanto nacionais, quanto migrantes que lá viviam, a deixar o país (FERNANDES, 2014).

Sobre a reportagem: um refugiado nacional da Guiné era apontado pela suspeita de ter contraído o vírus ebola antes de chegar ao Brasil. Apresentando sintomas semelhantes aos ocasionados pelo vírus, o refugiado deu entrada no sistema público de saúde de Cascavel, cidade localizada no Paraná, na região Sul do Brasil, local onde naquela circunstância residia em um abrigo. Além de ter apresentado imagens do refugiado, a reportagem também forneceu informações sobre a identidade dele e o percurso que havia feito quando deu entrada no país. Um dos pontos da narrativa que chama a atenção encontra-se descrito abaixo:

Imagens gravadas pela câmera de segurança da Unidade de Pronto Atendimento (UPA) de Cascavel, no Paraná mostram [nome do refugiado] esperando por quatro horas até ser atendido na última quintafeira (9). Tempo suficiente para ter contato com diversas pessoas que também estavam na UPA. Segundo a Secretaria de Saúde do Paraná, todas essas pessoas estão sendo monitoradas até o diagnóstico final do africano. [...] Na quinta passada, dia 9 de outubro, o africano procurou atendimento. Ele tinha febre, dor de garganta e tosse. A partir daí, uma operação de emergência foi montada. A suspeita era que ele estivesse contaminado com o vírus ebola. (FANTÁSTICO, 2014, grifo nosso ${ }^{3}$ ).

É possível identificar, durante a leitura da narrativa jornalística presente no site do "Fantástico", juntamente com a reportagem em vídeo, brechas textuais e imagéticas que podem induzir o público a suspeitar do refugiado. Ainda que naquele momento não houvesse a confirmação da suspeita de ebola por parte das autoridades de saúde, a acusação presente na narrativa pôs o refugiado em uma situação de vulnerabilidade, afetando sua moral, o que em nossa visão corrobora para a criação de um pânico moral por parte dos internautas e espectadores.

\footnotetext{
${ }^{3} \mathrm{O}$ nome do refugiado foi suprimido deste trecho em respeito à sua privacidade.
}

INTERIN, v. 22, n. 1, jan./jun. 2017. ISSN: 1980-5276. 
Fig. 1 - Frame da reportagem do "Fantástico", exibida pela Rede Globo em 12 de outubro de 2014 e que mostra o refugiado em destaque

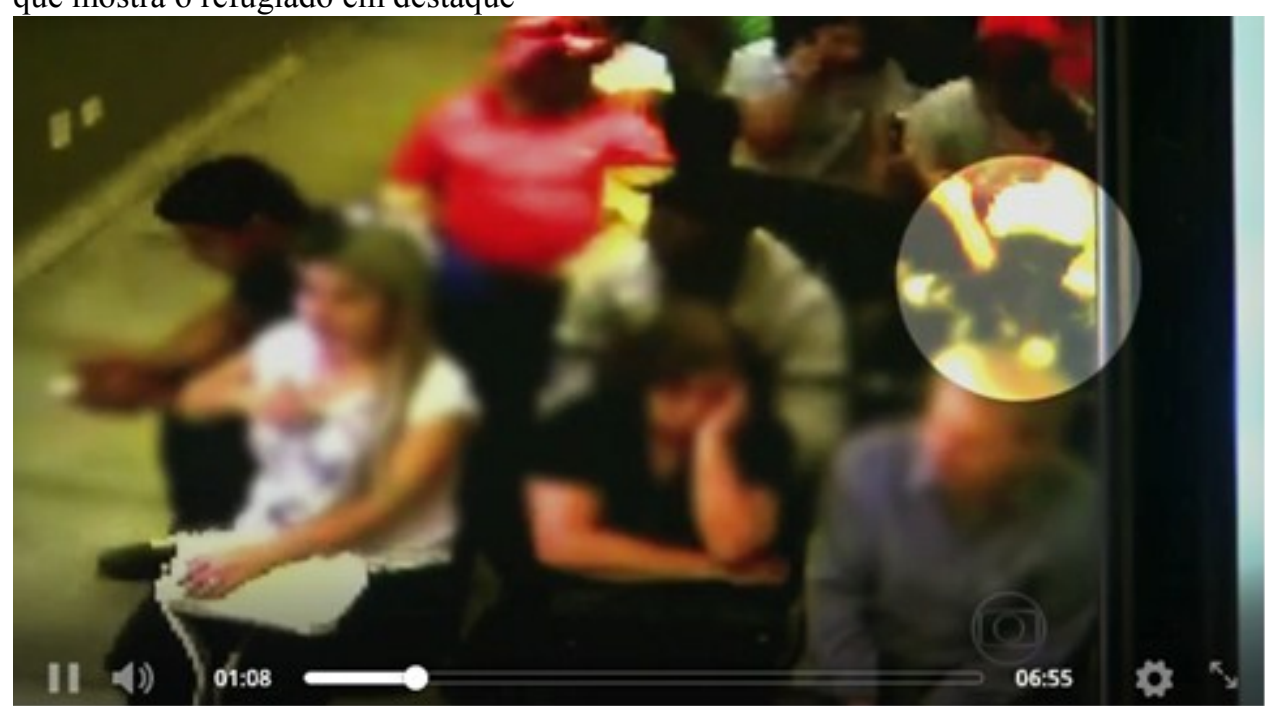

Fonte: imagem capturada na rede ${ }^{4}$.

As imagens audiovisuais utilizadas na reportagem, provenientes de câmeras de segurança instaladas no posto de saúde onde o refugiado aguardou e recebeu o primeiro atendimento médico, foram apropriadas na narrativa de modo tal que o refugiado aparecesse como suspeito de um crime. De forma sensacionalista, a narrativa jornalística promoveu um pânico de ordem moral nos espectadores, seja os que assistiram pela televisão ou na posterior veiculação da reportagem no site da revista eletrônica, fazendo uma superexposição da pessoa e a colocando sob suspeita de uma doença que não possuía, como foi comprovado por exames posteriores, os quais deram resultado negativo para o vírus ebola (NUBLAT, 2014).

A segunda reportagem analisada, publicada no dia 19 de outubro de 2014 no site do "Jornal do Brasil" vai além e, mesmo após uma extensa divulgação dos resultados negativos sobre o primeiro caso de suspeita de ebola no Brasil por parte de outros veículos jornalísticos brasileiros, pôs em suspeição outros imigrantes e refugiados que entraram no país de forma indocumentada. Com a manchete "Refugiados e imigrantes ilegais elevam o risco de entrada de ebola no país", a reportagem expôs em sua narrativa questões que podem induzir as pessoas a um

\footnotetext{
${ }^{4}$ Disponível em: < http://g1.globo.com/fantastico/noticia/2014/10/africano-com-suspeita-de-ebolaesperou-por-4-horas-ate-ser-atendido.html>. Acesso em: 19/12/2016.
}

INTERIN, v. 22, n. 1, jan./jun. 2017. ISSN: 1980-5276.

Samira Moratti Frazão; Gláucia de Oliveira Assis. Análise de representações de fluxos migratórios contemporâneos na narrativa jornalística brasileira sob a perspectiva do conceito de pânico moral. p. 111-130. 
pânico de ordem moral contra imigrantes e refugiados, especialmente aqueles de origem africana ou negros de outras nacionalidades, como é o caso de imigrantes caribenhos vindos do Haiti (JORNAL DO BRASIL, 2014).

Antes de prosseguir, é importante frisar que termos como "invasão", “ilegais", “indocumentados", "clandestinos", “chegada em massa" e "leva” possuem conotação pejorativa e podem influenciar, portanto, o modo como os migrantes podem ser vistos (COGO; SOUZA, 2013), promovendo, com isso, a ideia de pânico moral.

Com um discurso marcado pelo fator da segurança nacional, sugerindo o controle das fronteiras brasileiras, somado a utilização de um campo semântico discriminatório, a reportagem foi marcada por uma ausência de respeito aos Direitos Humanos, ao direito de migrar e ao direito à privacidade do refugiado, cuja suspeita da doença já havia sido negada por outros meios de comunicação (como, por exemplo, NUBLAT, 2014):

Contudo, apesar de [nome do refugiado] ter entrado no país de forma tradicional, um medo que pode surgir na população é da entrada de imigrantes de forma ilegal no país, muitas vezes junto aos migrantes vindos do Haiti. Nos últimos anos, mais de 25 mil haitianos entraram no país: só nos quatro primeiros meses de 2014, 7,3 mil haitianos vieram para o Brasil. [...] O infectologista ressalta que os problemas médicos relativos à pouca fiscalização das fronteiras é muito anterior ao medo da entrada de ebola. "Reforçar fronteiras é uma coisa que já deveria ter sido feita a muito tempo, por conta da entrada de drogas e armas que causam vários problemas à saúde do usuário de drogas, por exemplo. A fragilidade da fronteira já é algo que compromete a saúde brasileira há muito tempo. Não sei se agora por conta do ebola vai começar a melhorar, mas eu gostaria que isso acontecesse", denuncia. (JORNAL DO BRASIL, 2014, grifo nosso).

Ainda que em ambas as reportagens não houvesse o campo de comentários, em outras analisadas e que integram o corpus de análise total (composto por 68 selecionadas) foi possível encontrar exemplos de comentários feitos por internautas e que apresentam discursos de ódio contra os imigrantes e refugiados representados na narrativa jornalística. Como exemplo, cita-se a reportagem intitulada "Africano deu endereço errado no PR ao dar entrada em pronto-socorro", publicada na versão digital do jornal "Folha de São Paulo" em 10 de outubro de 2014, em que alguns dos

INTERIN, v. 22, n. 1, jan./jun. 2017. ISSN: 1980-5276.

Samira Moratti Frazão; Gláucia de Oliveira Assis. Análise de representações de fluxos migratórios contemporâneos na narrativa jornalística brasileira sob a perspectiva do conceito de pânico moral. p. 111-130. 
comentários apresentam elementos que corroboram para a exigência de um controle e fechamento de fronteiras no Brasil, como o feito pelo usuário "jrs" em 10 de outubro de 2014, às 13h39: “Com tantos imigrantes africanos pedindo refúgio ao Brasil em breve teremos novos casos de ebola por aqui" (CRUZ, 2014). Ainda que o caso naquele momento não tivesse nenhuma confirmação por parte das autoridades médicas, se era ou não real, com base em suspeitas alardeadas pelos meios de comunicação, os internautas poderiam assumir um pânico moral contra imigrantes e refugiados.

\section{Considerações finais}

Com base nas recomendações expostas no "Guia das Migrações Transnacionais e Diversidade Cultural para Comunicadores - Migrantes no Brasil”, de autoria das pesquisadoras Denise Cogo e Maria Badet Souza, é aconselhado nas coberturas jornalísticas que abarquem o tema dos fluxos migratórios

focalizar [a] migração como tema; abordar [a] migração como experiência
sociocultural; potencializar [a] migração como fonte em notícias de
interesse geral da sociedade; buscar fontes migrantes nacionais e
internacionais [e] incluir a perspectiva de gênero como importante para
não reforçar a desigualdade. (COGO; SOUZA, 2013, p. 61, grifo nosso).

Entre as cautelas e fatores a se evitar, está a de "não vitimizar os migrantes", entendendo que "embora parte das migrações sejam motivadas por fatores econômicos, é importante, na cobertura das migrações, não enfatizar apenas aspectos relacionados às situações de carência e precariedade vividas pelos migrantes" (COGO; SOUZA, 2013, p. 61).

Retomando a análise das duas reportagens aqui apresentadas, notou-se uma preocupação implícita sobre a presença de imigrantes e refugiados, especialmente os africanos ou negros de outras nacionalidades, como possíveis portadores de doenças, colocando, portanto, os brasileiros em risco. Este tipo de ocorrência pode levar o

INTERIN, v. 22, n. 1, jan./jun. 2017. ISSN: 1980-5276.

Samira Moratti Frazão; Gláucia de Oliveira Assis. Análise de representações de fluxos migratórios contemporâneos na narrativa jornalística brasileira sob a perspectiva do conceito de pânico moral. p. 111-130. 
público a um pânico de ordem moral contra os imigrantes e refugiados, que em muitos casos se encontram em situação de vulnerabilidade.

Somado à existência de fatores como o racismo, pode-se afirmar que tais narrativas midiáticas podem fomentar não apenas discursos de ódio contra migrantes, como também pôr em risco sua integridade física, nas comunidades onde estão vivendo ou nas quais estão em mobilidade, risco elevado quando sua imagem, por meio de foto ou registro audiovisual ou ainda informações que os identifiquem, são registradas e apresentadas.

Desse modo, entende-se que o jornalismo pode praticar um desserviço à sociedade ao disseminar suspeitas sem confirmação, atribuindo ao que e/ou quem está sendo noticiado julgamentos não apenas midiáticos, como morais por parte da sociedade. No caso dos fluxos migratórios contemporâneos, se por um lado um contra-agendamento é realizado por organizações da sociedade civil, entidades públicas e privadas e mídias alternativas que visam a integração de imigrantes e refugiados, de outro tais construções da realidade como as aqui analisadas podem, na contramão, difícultar o processo de acolhimento.

\section{REFERÊNCIAS}

ACNUR - Alto Comissariado das Nações Unidas para Refugiados (ACNUR). Protocolo de 1967 relativo ao Estatuto dos Refugiados publicado em 4 out. 1967. Disponível em: $<$ http://www.acnur.org/t3/portugues/recursos/documentos/?tx_danpdocumentdirs_pi $2 \% 5 \mathrm{Bmode} \% 5 \mathrm{D}=1 \&$ tx_danpdocumentdirs_pi $2 \% 5 \mathrm{Bsort} \% 5 \mathrm{D}=$ doctitle,sorting,uid\&t x_danpdocumentdirs_pi $2 \% 5$ Bsword $\% 5 \mathrm{D}=$ protocolo\%201967\&tx_danpdocumentdir s_pi2\%5Bfromsearch $\% 5 \mathrm{D}=\mathrm{Y} \& \mathrm{tx}$ _danpdocumentdirs_pi $2 \% 5 \mathrm{Bdownload} \% 5 \mathrm{D}=\mathrm{yes} \& \mathrm{t}$ x_danpdocumentdirs_pi $2 \% 5$ Bdownloadtyp $\% 5 \mathrm{D}=$ stream\&tx_danpdocumentdirs_pi2 $\% 5$ Buid\%5D=595>. Acesso em: 17/01/2016.

O que é a Convenção de 1951? 2015a. Disponível em:

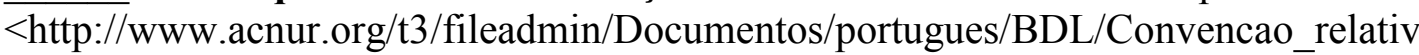
a_ao_Estatuto_dos_Refugiados.pdf $>$. Acesso em: 20/12/2016.

INTERIN, v. 22, n. 1, jan./jun. 2017. ISSN: 1980-5276.

Samira Moratti Frazão; Gláucia de Oliveira Assis. Análise de representações de fluxos migratórios contemporâneos na narrativa jornalística brasileira sob a perspectiva do conceito de pânico moral. p. 111-130. 


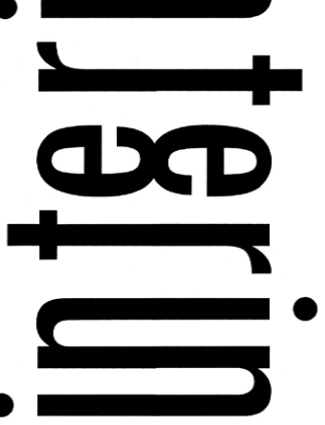

. Perguntas e respostas, 2015b. Disponível em: $<\mathrm{http} / /$ www.acnur.org/t3/portugues/informacao-geral/perguntas-e-respostas/>. Acesso em: 20/12/2016.

. Dados sobre refúgio no Brasil - Balanço até abril de 2016. Disponível em: $\quad<$ http://www.acnur.org/t3/portugues/recursos/estatisticas/dados-sobre-refugiono-brasil/>. Acesso em: 19/12/2016.

AMOSSY, R. Estereótipo. In: CHARAUDEAU, P.; MAINGUENEAU, D. Dicionário de análise do discurso. São Paulo: Contexto, 2014, p. 214-216.

ASSIS, G. O.; MAGALHÃES, L. F. A. Migrantes indesejados? A "diáspora" haitiana no Brasil e os desafios à política migratória brasileira. In: SILVA, S. A.; ASSIS, G. O. (Orgs.). Em busca do Eldorado: o Brasil no contexto das migrações nacionais e internacionais. Manaus: EDUA, 2016, p. 209-250.

BENTO, M. A. S. Branqueamento e Branquitude no Brasil. In: CARONE, I.; BENTO, M. A. S. (Orgs.). Psicologia social do racismo: estudos sobre branquitude e branqueamento no Brasil. Petrópolis: Vozes, 2002, p. 25-58.

BONA, A. N. História, verdade e ética: Paul Ricoeur e a epistemologia da História. Guarapuava: Unicentro, 2012.

BRASIL. Lei n. 9.474 de 22 de julho de 1997. Define mecanismos para a implementação do Estatuto dos Refugiados de 1951, e determina outras providências. Diário Oficial da União, Brasília, DF, 28 julh. 1997, Seção 1, p.15822. Disponível em: <https://www.planalto.gov.br/ccivil_03/leis/19474.htm>. Acesso em: 10/12/2014.

CHARAUDEAU, P. Representação social. In: CHARAUDEAU, P.; MAINGUENEAU, D. Dicionário de análise do discurso. 3 ed. São Paulo: Contexto, 2014, p. 431-433.

CHARTIER, R. A historia cultural entre práticas e representações. Rio de Janeiro: Bertrand Brasil; Lisboa: Difel, 1990.

. O mundo como representação. Estudos Avançados, v. 5, n. 11. São Paulo: jan.-abril, 1991. Disponível em: <http://www.scielo.br/scielo.php?pid=S010340141991000100010\&script=sci_arttext $>$. Acesso em: 2/12/2014.

COGO, D; SOUZA, M. Guia das migrações transnacionais e diversidade cultural para comunicadores: migrantes no Brasil. Belatterra: Instituto de la Comunicación de la UAB/Instituto Humanitas Unisinos, 2013.

INTERIN, v. 22, n. 1, jan./jun. 2017. ISSN: 1980-5276.

Samira Moratti Frazão; Gláucia de Oliveira Assis. Análise de representações de fluxos migratórios contemporâneos na narrativa jornalística brasileira sob a perspectiva do conceito de pânico moral. p. 111-130. 
CRUZ, L. C. Africano deu endereço errado no PR ao dar entrada em pronto-socorro. Folha de S. Paulo, 10 out. 2014. Disponível em: $<$ http://www1.folha.uol.com.br/cotidiano/2014/10/1530403-africano-deu-enderecofalso-no-parana-ao-dar-entrada-em-pronto-socorro.shtml>. Acesso em: 19/12/2016.

FANTÁSTICO. Africano com suspeita de ebola esperou por 4 horas até ser atendido. Fantástico - G1, 12 out. 2014. Disponível em: $<$ http://g1.globo.com/fantastico/noticia/2014/10/africano-com-suspeita-de-ebolaesperou-por-4-horas-ate-ser-atendido.html >. Acesso em: 19/12/2016.

FERNANDES, D. Ebola: embaixada na Guiné concede cerca de 40 vistos por mês para o Brasil. BBC Brasil, 11 out. 2014. Disponível em: $<$ http://www.bbc.com/portuguese/noticias/2014/10/141011_ebola_vistos_guine $>$.

Acesso em: 19/12/2016.

HERSCOVITZ, H. G. Análise de conteúdo em jornalismo. In: LAGO, C.; BENETTI, M. (Orgs). Metolodogia de pesquisa em jornalismo. Petrópolis: Vozes, 2007, p. 123-142.

JORNAL DO BRASIL. Refugiados e imigrantes ilegais elevam o risco de entrada de ebola no país. Jornal do Brasil, 19 out. 2014. Disponível em: $<$ http://www.jb.com.br/ciencia-e-tecnologia/noticias/2014/10/19/refugiados-eimigrantes-ilegais-elevam-o-risco-de-entrada-de-ebola-no-pais/>. Acesso em: $15 / 09 / 2016$.

MOTA, C. L. A narrativa semiótica da imagem. In: MOTA, C. L. et al. (Orgs.). Narrativas midiáticas. Florianópolis: Insular, 2012, p. 197-215.

MOTTA, L. G. Por que estudar narrativas? In: MOTA, C. L. et al. (Orgs.). Narrativas midiáticas. Florianópolis: Insular, 2012, p. 23-32.

NUBLAT, J. Resultado de segundo exame descarta caso de ebola no Brasil. Folha de S. Paulo, 13 out. 2014. Disponível em: $<$ http://www1.folha.uol.com.br/cotidiano/2014/10/1531725-segundo-examedescarta-suspeita-de-ebola-em-homem-da-guine.shtml>. Acesso em: 16/09/2016.

RICHARD, I. Ebola: imigrantes negros são discriminados depois de caso suspeito em Cascavel. Agência Brasil, 16 out. 2014. Disponível em: $<$ http://agenciabrasil.ebc.com.br/direitos-humanos/noticia/2014-10/ebola-imigrantesnegros-sao-discriminados-no-brasil-depois-de-caso $>$. Acesso em: 19/12/2016.

THOMPSON, K. Panicos morales. 1. ed. Bernal: Universidad Nacional de Quilmes, 2014. 
VIZEU, A. O telejornalismo como lugar de referência e a função pedagógica. Revista Famecos, Porto Alegre, n. 40, p. 77-83, dez. 2009.

Recebido em: 20.12.2016

Aceito em: 31.03 .2017

INTERIN, v. 22, n. 1, jan./jun. 2017. ISSN: 1980-5276.

Samira Moratti Frazão; Gláucia de Oliveira Assis. Análise de representações de fluxos migratórios contemporâneos na narrativa jornalística brasileira sob a perspectiva do conceito de pânico moral. p. 111-130. 